\title{
TRÁFICO DE ANIMAIS SILVESTRES E SEUS PRODUTOS NO EXTREMO OESTE BRASILEIRO
}

\author{
Gilcineide Araujo Pires ${ }^{1}$ \\ Suelen Ferreira da Costa Rodrigues ${ }^{1}$ \\ Kelen Rodrigues Macedo ${ }^{1}$ \\ Angela Maria Fortes de Andrade ${ }^{2}$ \\ Itacir Olivio Farikoski ${ }^{3}$ \\ Henrique Jorge de Freitas ${ }^{4}$ \\ Vania Maria França Ribeiro ${ }^{5}$
}

PIRES, G. A.; RODRIGUES, S. F. da C.; MACEDO, K. R.; ANDRADE, A. M. F. de; FARIKOSKI, I. O.; FREITAS, H. J. de; RIBEIRO, V. M. F. Tráfico de animais silvestres e seus produtos no extremo oeste brasileiro. Arq. Ciênc. Vet. Zool. UNIPAR, Umuarama, v. 18, n. 4, p. 241-245, out./dez. 2015.

RESUMO: O tráfico de animais silvestres vivos e abatidos no estado do Acre ocorre constantemente. Notadamente a fauna silvestre está perdendo a batalha com a exploração desenfreada nesta região, uma vez que a carne de animais silvestres é importante fonte proteica e muitas pessoas alegam que praticam a caça como forma de subsistência. No entanto, a maioria das apreensões feitas pelos órgãos competentes pertence à avifauna acriana. Estas oriundas de atividades ilícitas, e se não interceptadas iriam abastecer o mercado ilegal, seriam exportadas e vendidas a preços exorbitantes. Diante do acentuado índice de ocorrência de autuações sobre tráfico de animais silvestres, vale ressaltar que a sociedade e as comunidades locais têm papel fundamental na conscientização de que os animais silvestres podem ser extintos devido à caça predatória.

PALAVRAS-CHAVE: Ambiental. Comércio. Fauna. Ilegalidade. Silvestre.

\section{TRAFFICKING OF WILD ANIMALS AND THEIR PRODUCTS IN THE FAR WEST BRAZILIAN}

ABSTRACT: Trafficking of live wild animals and slaughtered in Acre occurs constantly. Notably the wildlife is losing the battle with the unbridled exploitation in this region, since the meat of wild animals is important protein source and many people claim that practice hunting for subsistence. But most of the seizures made by the competent bodies belongs to acriana avifauna. These derived from illicit activities, and if not intercepted would supply the illegal market, would be exported and sold at exorbitant prices. Before the sharp assessments of occurrence index on wildlife trafficking, it is noteworthy that society and local communities have a vital role in awareness that wild animals may be extinct due to poaching.

KEYWORDS: Environmental. Fauna. Illegality .Trade. Wildlife.

\section{TRÁFICO DE ANIMALES SILVESTRES Y SUS PRODUCTOS EN EL EXTREMO OESTE BRASILEÑO}

RESUMEN: El tráfico de animales silvestres vivos y sacrificados en el estado de Acre ocurre constantemente. Especialmente la fauna silvestre está perdiendo la batalla con la desenfrenada explotación en esa región, una vez que la carne de animales silvestres es una importante fuente de proteínas y muchas personas afirman que practican la caza como medio de subsistencia. Sin embargo, gran parte de las incautaciones hechas por los órganos competentes pertenecen a la avifauna del estado de Acre. Estos provienen de actividades ilegales que, si no fuera interceptada, abastecería el mercado ilegal, serian exportadas y vendidas a precios exorbitantes. Dada las altas tasas de ocurrencia de aprehensiones en el tráfico de animales silvestres, se debe destacar que la sociedad y las comunidades locales tienen un papel fundamental en la concientización de que los animales silvestres pueden ser extinguidos debido a la caza depredadora.

PALABRAS CLAVE: Ambiental. Comercio. Fauna. Ilegalidad. Silvestre.

\section{Introdução}

A Floresta Amazônica possui uma das mais ricas biodiversidades do mundo. $\mathrm{O}$ estado do Acre integra a região Amazônica e está situado no extremo oeste brasileiro, fazendo fronteira com o Peru e a Bolívia e divisa com os estados do Amazonas e de Rondônia, apresentando uma área de aproximadamente $164.123,739 \mathrm{~km}^{2}$, composto por $22 \mathrm{mu}-$ nicípios (IBGE, 2015). Pela vasta riqueza de fauna e flora, é um dos estados que apresenta constante ocorrência de tráficos de animais silvestres e tem uma importância estratégica para o tráfico, pois existem rotas que passam pelo estado abrangendo os países vizinhos.

De acordo com a lei de crime ambiental de tráfico de animais silvestres regulada no Decreto: Lei 9.605/98, descrita no Artigo 29, é considerado tráfico de animais silvestres: ma-

DOI: https://doi.org/10.25110/arqvet.v18i4.2015.5751

${ }^{1}$ Engenheira Agrônoma. Mestranda em Sanidade e Produção Animal Sustentável na Amazônia Ocidental pela Universidade Federal do Acre UFAC. Avenida Maria José de Oliveira, nº 840, CJ Universitário II, 69.917-680. Rio Branco, Acre. gilce.pires@gmail.com

${ }^{2}$ MédicaVeterinária. Mestranda em Sanidade e Produção Animal Sustentável na Amazônia Ocidental pela Universidade Federal do Acre - UFAC.

${ }^{3}$ Biólogo. Mestrando em Sanidade e Produção Animal Sustentável na Amazônia Ocidental pela Universidade Federal do Acre- UFAC.

${ }^{4}$ Médico Veterinário. Mestre e Doutor em Zootecnia pela Universidade Federal de Lavras. Professor da UFAC.

${ }^{5}$ Médica Veterinária. Mestre em Medicina Veterinária pela Universidade Federal de Pernambuco. Doutora em Biotecnologia pela Universidade Federal do Amazonas. Professora associada da UFAC. 
tar, perseguir, caçar, apanhar, utilizar espécimes da fauna silvestre, nativos ou em rota migratória, sem a devida permissão, licença ou autorização dos órgãos competentes do Estado. E assim, integra o ciclo do tráfico de animais silvestres, qualquer atividade voltada também ao comércio de espécimes da fauna silvestre sem a devida autorização dos órgãos competentes.

A comercialização ilegal da fauna silvestre e seus subprodutos são caracterizados por intensa movimentação, ocorrendo em diversas áreas e os animais destinados para diferentes locais. No tráfico de animais silvestres existem os países exportadores e aqueles países consumidores (INSAURALDE et al., 2010).

Uma das formas em transformar os animais silvestres em fontes renováveis, além de reduzir as ameaças à extinção é por meio da implantação de criadouros autorizados, fazendas de caça esportiva e reprodução autorizada dos animais em cativeiro (ODA et al., 2004).

Nesse contexto, o objetivo deste trabalho foi avaliar que espécies da vida silvestre e seus produtos estão sendo comercializados de forma ilegal no estado do Acre, entre o período de 2009 a 2014, de acordo com o levantamento de dados feito pelo Batalhão de Polícia Ambiental do estado do Acre.

\section{Material e Métodos}

Os dados foram repassados pelo Batalhão de Polícia Ambiental do Estado do Acre - BPA/AC, registrados no período entre 2009 a 2014, resultados dos registros de fiscalizações, apreensões de animais silvestres e seus produtos no comércio ilegal.

Na pesquisa foram computados: quantidade de animais apreendidos, nome popular da espécie, sexo e idade do infrator, ano de ocorrência e municípios onde foram feitas as apreensões. Após coleta, os dados foram tabulados utilizando-se do programa computacional Excel da Microsoft Office para a confecção de gráficos e tabelas.

\section{Resultados e Discussão}

No período estudado, obteve-se um total de 429 espécimes apreendidas. As apreensões ocorreram em sete municípios acrianos: Acrelândia (4/429; 1\%), Brasiléia (4/429; $1 \%)$, Bujari $(69 / 429 ; 16 \%)$, Porto Acre $(34 / 429 ; 8 \%)$, Rio Branco (262/429; 61\%), Sena Madureira (13/429; 3\%) Sena- dor Guiomard (43/429; 10\%), com destaque para Rio Branco onde concentrou a maioria das autuações.

As regiões fronteiriças do estado do Acre favorecem o intenso contrabando de animais silvestres, ocasionado principalmente pelo pequeno efetivo para fiscalizar extensa área de fronteira, situada no extremo oeste da Região Norte do Brasil, fazendo fronteira com os Estados do Amazonas e Rondônia, e os países Peru e Bolívia. Sua superfície territorial é de $153.149,9 \mathrm{~km}^{2}$, que corresponde a $3,2 \%$ da Amazônia brasileira e 1,8\% do território nacional. Portanto, a fiscalização ambiental disponível encontra dificuldades de acesso em alguns locais onde ocorre o crime ambiental, pois estes animais são transportados de forma intensa por diversas rodovias, estradas e rios da região. As principais cidades que fornecem animais silvestres de forma ilegal de acordo com Renctas (2001), estão localizadas na região Amazônica, como Rio Branco (AC), Porto Velho (RO), Manaus (AM) e Bonfim (RR).

Dos indivíduos envolvidos no processo de captura de animais silvestres, $4,22 \%$ representaram a idade de até 20 anos, $61,60 \%$ de 21 a 40 anos e 34,18\% foram os indivíduos com idade acima de 40 anos, sendo estes definidos em $94 \%$ do sexo masculino e $6 \%$ do sexo feminino.

No comércio ilegal de produtos e subprodutos da fauna, segundo Renctas (2001), há três formas de tráfico, iniciando pelos fornecedores, seguido dos intermediários e por fim consumidores finais. Este último varia de acordo com finalidade do animal capturado e que há casos que, quanto mais ameaçados de extinção e a raridade da espécie, mais elevada será a cotação.

Muitos são comercializados por meio de venda direta em estradas, margens de rios, internet, pet shops e feiras ilegais (HERNANDEZ; CARVALHO, 2006). No caso do Acre, de acordo com informações fornecidas por membro do $\mathrm{BPA} / \mathrm{AC}$, mais de $90 \%$ das apreensões foram realizadas em margens de rodovias e estradas vicinais.

Na Tabela 1 podem-se observar as espécies apreendidas, bem como a quantidade por ano. Entre estas, constam algumas espécies ameaçadas de extinção, de acordo com a lista nacional oficial de espécies da fauna ameaçadas de extinção de 2014 (IBAMA, 2015), tais como a anta - Tapirus terrestres, macaco guariba - Alouatta ululata elliot, macaco prego - Sapajus cay e queixada - Tayassu pecari.

Tabela 1: Animais apreendidos entre os anos de 2009 a 2014 no estado do Acre, segundo dados obtidos pelo Batalhão de Polícia Ambiental do estado do Acre.

\begin{tabular}{|c|c|c|c|c|c|c|}
\hline Espécies/Ano & 2009 & 2010 & 2011 & 2012 & 2013 & 2014 \\
\hline Anta - Tapirus terrestris & 0 & 0 & 0 & 0 & 0 & 1 \\
\hline Bicho preguiça - Bradypus tridactylus & 1 & 1 & 0 & 0 & 0 & 0 \\
\hline Cágado-Mauremys caspica & 0 & 0 & 0 & 1 & 0 & 0 \\
\hline Capivara - Hydrochoerus hydrochaeris & 2 & 0 & 1 & 6 & 6 & 2 \\
\hline Cateto - Tayassu tajacu & 3 & 2 & 0 & 0 & 2 & 2 \\
\hline Coruja - Athene cunicularia & 1 & 0 & 0 & 0 & 0 & 0 \\
\hline Curica - Amazona amazonica & 0 & 3 & 0 & 0 & 0 & 0 \\
\hline Curió - Oryzoborus angolensis & 23 & 41 & 19 & 37 & 73 & 14 \\
\hline Cutia - Dasyprocta leporina & 1 & 1 & 1 & 1 & 1 & 2 \\
\hline Gavião carijó - Rupornis magnirostris & 1 & 0 & 1 & 0 & 0 & 0 \\
\hline
\end{tabular}


Inhambu galinha - Tinamus guttatus

\begin{tabular}{lcccccc} 
Inhambu galinha - Tinamus guttatus & 1 & 0 & 0 & 0 & 0 & 0 \\
Jabuti - Chelonoidis denticulata & 3 & 1 & 7 & 1 & 6 & 4 \\
Jacaré - Melanosuchus niger & 0 & 0 & 1 & 2 & 6 & 3 \\
Jacu - Penelope jacquacu & 0 & 0 & 1 & 0 & 0 & 1 \\
Jiboia - Boa constrictor & 0 & 1 & 0 & 3 & 0 & 0 \\
Macaco guariba - Alouatta ululata elliot & 0 & 0 & 1 & 0 & 0 & 1 \\
Macaco prego - Sapajus cay & 2 & 0 & 2 & 1 & 1 & 1 \\
Mergulhão-Tachybaptus domunicus & 0 & 0 & 1 & 0 & 0 & 0 \\
Mutum Cavalo - Pauxi tuberosa & 0 & 0 & 0 & 0 & 0 & 3 \\
Paca - Agouti paca & 9 & 2 & 6 & 2 & 13 & 11 \\
Paca de rabo - Dinomys branickii & 0 & 0 & 0 & 1 & 0 & 0 \\
Papagaio - Amazona aestiva & 3 & 2 & 0 & 2 & 0 & 0 \\
Pato selvagem - Cairina moschata & 0 & 0 & 0 & 0 & 0 & 3 \\
Periquito estrela - Brotogeris versicolurus & 0 & 16 & 0 & 0 & 1 & 0 \\
Quatipuru - Sciurus igniventris & 0 & 0 & 0 & 0 & 1 & 0 \\
Queixada - Tayassu pecari & 0 & 0 & 0 & 1 & 1 & 0 \\
Socó - Butorides striatus & 0 & 0 & 0 & 0 & 0 & 1 \\
Tamanduá - Myrmecophaga tridactyla & 0 & 1 & 0 & 1 & 1 & 0 \\
Tartaruga da Amazônia - Podocnemis expansa & 1 & 0 & 0 & 0 & 0 & 0 \\
Tatu - Priodontes & 1 & 0 & 4 & 5 & 17 & 16 \\
Veado vermelho - Cervus elaphus & 0 & 0 & 1 & 1 & 0 & 1 \\
\hline
\end{tabular}

Fonte: boletins repassados pelo Batalhão de Polícia Ambiental (BPA) do estado do Acre.

As principais espécies apreendidas podem ser observadas na Figura 1, com as respectivas porcentagens.

Figura 1: Animais silvestres mais capturados pelo Batalhão de Polícia Ambiental do estado do Acre, no período de 2009 a 2014.

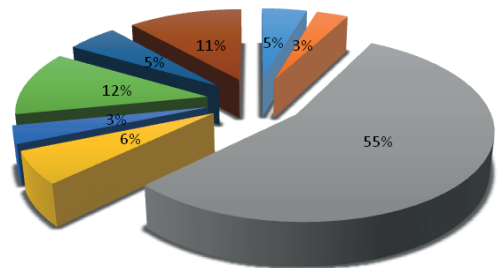

De acordo com a Figura 1, as espécies mais procuradas foram: curió, paca, tatu, jabuti, periquito, capivara, cateto e jacaré. Com o passar dos anos, a captura em excesso poderá ocasionar a redução dessas espécies silvestres. A paca, por exemplo, possui uma baixa taxa reprodutiva, de um a dois filhotes por ano e raramente apresenta parto gemelar, conforme citado por Hosken e Silveira (2001).

Apreensões realizadas pelo policiamento ambiental nos municípios do Acre, durante os anos de 2009 a 2014, mostraram que 250 dos animais comercializados eram aves. Esses dados se assemelham com o estudo realizado por Souza et al. (2014), em que foram analisados 2.391 termos e diagnosticadas 11.318 aves pertencentes a 162 espécies e 33 famílias, evidenciando intensa predação sobre a avifauna em Minas Gerais. Uma das justificativas pode estar relacionada ao fato das aves serem donas de extraordinária beleza que encantam os amantes de pássaros de gaiola (BARBOSA et al., 2010).

No Acre, das 250 aves apreendidas no período em estudo, 55\% eram curiós. Segundo Machado et al. (2008), esses pássaros são procurados pela beleza de seus cantos, porém, essas aves ainda não constam nas listas entre as espécies ameaçadas de extinção. Segundo Almeida et al. (2012) em pesquisa com 44 moradores do interior e entorno do Parque Nacional Serra do Divisor - Acre, os animais vistos com maior frequência na atividade da caça são pacas, cotias, tatus e veados. Essa análise faz concordância com parte dos dados apresentados na Figura 1, de acordo com apreensões realizadas pelo BPA/AC. Segundo Pereira e Schiavetti (2010), a paca e o tatu estão na lista dos animais capturados, apreciados pela carne de sabor característico, sendo que o tatu é um dos animais silvestres encontrado com maior frequência na região.

A capivara representa a espécie de médio a grande porte, sendo abatida para o consumo. De acordo com Almeida et al. (2012) apesar dessa espécie ter perdido seu hábitat natural pela influência urbana, observa-se ainda comportamentos como termorregulação e marcação de território semelhantes às que vivem em seu ambiente natural.

O cateto é uma espécie que pode ser criada em cativeiros autorizados para fins econômicos (CRUZ et al., 2015) e segundo Albuquerque et al. (2009), a carne de catetos é considerada uma fonte alternativa de proteína.

De acordo com Silva (2007), a carne de animal silvestre é apreciada por serem consideradas iguarias, saindo da monotonia da alimentação diária. Dentre as ocorrências do BPA/AC, consta a apreensão de quase $50 \mathrm{Kg}$ de carne de diversos animais.

Os produtos de animais silvestres também são empregados no preparo de outros itens, como para fins medici- 
nais, por exemplo, os indígenas Kaxinawá e os Ashaninka localizados no Alto Juruá do estado do Acre utilizam a bílis da paca no tratamento de picadas de cobra e para estágios febris da comunidade (ALMEIDA et al., 2002).

Ao se observar a Figura 2, nota-se uma variação na quantidade de apreensões por ano. Uma fiscalização e mesmo registros mais ou menos efetivos podem ter corroborado para este achado.

Figura 2: Apreensões (\%) anuais de animais silvestres feito pelo BPA/AC no período de 2009 a 2014.
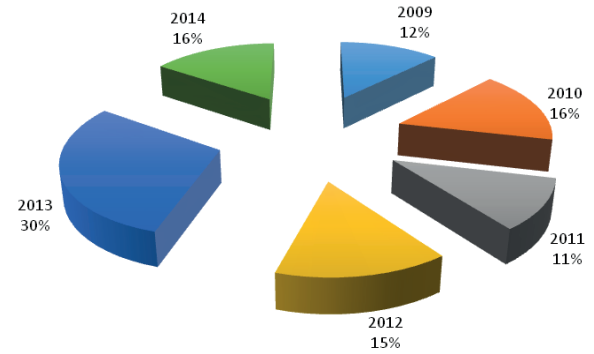

Estudos feitos em duas comunidades situadas no Parque Nacional da Serra do Divisor possibilitaram averiguar em entrevistas com 134 moradores que, 66\% desses têm praticado a caça de animais silvestres e 34\% não caçam. Muitos indivíduos alegam que caçam somente para consumo próprio, porém a caça praticada como meio de subsistência também causa sérias ameaças à conservação e ao equilíbrio da fauna (ALMEIDA et al., 2012).

No entanto, os animais bem como a carne apreendida, pareciam ser destinados ao comércio ilegal que é um dos grandes responsáveis pela extinção de diversas espécies de pássaros e outros animais pertencentes à fauna brasileira.

Acredita-se que com a dificuldade de fiscalização enfrentada pelos profissionais da área e o pouco investimento em combate a essa prática, torna o tráfico de fauna silvestre cada vez mais promissor, pois os riscos de infratores serem apanhados são menores e os lucros altos (RENCTAS, 2001).

\section{Conclusão}

Conclui-se que o tráfico de animais silvestres e seus produtos é uma realidade no extremo oeste brasileiro, principalmente devido à aceitação de mercado e que este firmemente, não sendo combatido na forma da lei, contribuirá para a extinção das espécies em estudo, principalmente àquelas que já constam na lista nacional oficial de espécies da fauna brasileira ameaçadas de extinção. Uma das maneiras de se mudar este prognóstico é a criação de espécies silvestres em criatórios legalizados onde apenas animais nascidos em cativeiro possam ser devidamente comercializados bem como seus produtos e subprodutos.

\section{Referências}

ALBUQUERQUE, N. I. et al. Propriedades da carne e perfil de ácidos graxos do pernil de catetos (Tayassutajacu) alimentados com torta de babaçu (Orbignyaphalerata).

Arquivo Brasileiro de Medicina Veterinária e Zootecnia, Belo Horizonte, v. 61, n. 6, p. 1419-1427, 2009.
ALMEIDA, A. M. R.; BIONDI, D.; MONTEIRO-FILHO, E. A. L. Comportamento de capivaras em área verde urbana no município de Curitiba, PR. Revista Biociências, Taubaté, v. 18, n. 2, p. 24-31, 2012.

ALMEIDA, G. S. et al. Percepção das populações do interior e do entorno do Parque Nacional Serra do Divisor - Acre sobre a caça cinegética e seus efeitos sobre a abundância dos recursos faunísticos. Enciclopédia Biosfera, Centro Científico Conhecer, Goiânia, v. 8, n. 15, p. 1902-1912, 2012.

ALMEIDA, L. L. S. Da Cordilheira para a floresta. Povos do Acre: história Indígena da Amazônia Ocidental, p. 2627, 2002.

BARBOSA, J. A. A.; NOBREGA, V. A.; ALVES, R. R. N. Aspectos da caça e comércio ilegal da avifauna silvestre por populações tradicionais do semi-árido paraibano. Revista de Biologia e Ciências da Terra, Campina Grande, v. 10, n. 2, p. 39-49, 2010.

BRASIL. Lei no 9.605, de 12 de fevereiro de 1998. Lei de crime ambiental. Disponível em: $<$ http://www.planalto.gov. br/ccivil_03/LEIS/L9605.htm>. Acesso em: 17 jun. 2015.

CRUZ, M. P. et al. Estudo do cateto (Tayassu tajacu) e queixada (Tayassu pecari) no Parque Municipal das Araucárias (Guarapuava- Paraná): regime semicativeiro. Disponível em: <http://www.seb-ecologia.org.br/viiceb/ resumos/466a.pdf>. Acesso em: 29 jul. 2015.

HERNANDEZ, E. F. T.; CARVALHO, M. S. O tráfico de animais silvestres no Estado do Paraná. ActaScientiarum. Human and SocialSciences, Maringá, v. 28, n. 2, p. 257 266,2006

HOSKEN, F. M.; SILVEIRA, A. C. Criação de paca. Viçosa: Aprenda Fácil, 2001. 262 p.

IBAMA. Instituto Brasileiro do Meio Ambiente e dos Recursos Naturais Renováveis. Lista nacional oficial de espécies da fauna ameaçadas de extinção. Disponível em: $<$ http://pesquisa.in.gov.br/imprensa/jsp/visualiza/index.jsp? jornal $=1 \&$ pagina $=121 \&$ data $=18 / 12 / 2014>$. Acesso em: 17 jun. 2015.

IBGE. Instituto Brasileiro de Geografia e Estatística.

Informações sobre municípios brasileiros: Acre. Disponível em: <http://ibge.gov.br/cidadesat/xtras/uf.php?la ng=\&coduf $=12 \&$ search=acre $>$. Acesso em: 17 jun. 2015.

INSAURALDE, A. L. S.; GUIA, M. M. R.; FELIX, G. D. N. O tráfico de animais e suas consequências. In: ENCONTRO NACIONAL DOS GEÓGRAFOS, 16., 2010, Porto Alegre. Anais... Porto Alegre: AGB, 2010.

MACHADO, A. B. M.; DRUMMOND, G. M.; PAGLIA, A. P. Livro vermelho da fauna brasileira ameaçada de extinção. Brasília: Fundação Biodiversitas. 2008. p. 1420. 
ODA, S. H. I. et al. Efeitos dos métodos de abate e sexo na composição centesimal, perfil de ácidos graxos e colesterol da carne de capivaras. Ciência e Tecnologia de Alimentos, Campinas, v.24, n. 2, p. 236-242, 2004.

PEREIRA, J. P. R.; SCHIAVETTI, A. Conhecimentos e usos da fauna cinegética pelos caçadores indígenas "Tupinambá de Olivença” (Bahia). Biota Neotropica, v. 10, n. 1, p. 176-183, 2010.

RENCTAS - Rede Nacional Contra o Tráfico de Animais Silvestres. $\mathbf{1}^{\mathbf{0}}$ Relatório nacional sobre o tráfico de fauna silvestre, Brasília: 2001. 108 p.

SILVA, A. L. Comida de gente: preferências e tabus alimentares entre os ribeirinhos do Médio Rio Negro (Amazonas, Brasil). Revista de Antropologia, São Paulo, v. 50, n. $1,2007$.

SOUZA, T. O.; VILELA, D. A. R.; CÂMARA, B. G. O. Pressões sobre a avifauna brasileira: aves recebidas pelo CETAS/IBAMA, Ornithologia, Belo Horizonte, v. 7, n. 1, p.1-11, 2014.

Recebido em: 23.09.2015

Aceito em: 28.12.2015 